\title{
Analisis Areal Parkir pada SMK Negeri 5 Kota Pekanbaru
}

\author{
Mukhardi, Virgo Trisep Haris ${ }^{2}$, Fadrizal Lubis ${ }^{3}$ \\ Program Studi Teknik Sipil, Fakultas Teknik, Universitas Lancang Kuning \\ Jl. Yos Sudarso km. 8 Rumbai, Pekanbaru, Telp. (0761) 52324 \\ Email: adi.momo752@gmail.com., virgo@unilak.ac.id, fadrizal@unilak.ac.id.
}

\begin{abstract}
ABSTRAK
SMK Negeri 5 Pekanbaru merupakan salah satu pusat kegiatan dalam bidang pelayanan jasa untuk mengurus pendidikan di kawasan Kecamatan Rumbai Kota Pekanbaru Provinsi Riau. Salah satu masalah dari SMK Negeri 5 Pekanbaru ini adalah kebutuhan ruang parkir kendaraan untuk siswa. Meskipun sekolah ini memiliki lahan bebas yang memadai, tetapi pada kenyataannya masih banyak kendaraan siswa yang parkir disembarang tempat yang mengakibatkan menumpuknya kendaraan. Penelitian ini bertujuan untuk mengetahui apakah lahan bebas yang ada di SMK Negeri 5 Pekanbaru mampu menampung seluruh kendaraan siswa. Metode penelitian ini dilakukan dengan survei pada lokasi yang bersangkutan dan dari data yang ada pada pihak pengelola. Kemudian dilakukan analisa karakteristik parkir berupa: Volume parkir, akumulasi parkir, angka pergantian parkir dan indeks parkir. Hasil perhitungan yang di dapatkan volume parkir untuk kendaraan motor pada hari senin tanggal 12 maret 2018 sebanyak 523 kendaraan, untuk hari selasa tanggal 13 maret 2018 sebanyak 527 kendaraan, untuk hari rabu tanggal 14 maret 2018 sebanyak 530 kendaraan, untuk hari kamis tanggal 15 maret 2018 sebanyak 523 kendaran dan di hari jumat tanggal 16 maret 2018 sebanyak 526 kendaraan. Akumulasi motor terbesar terjadi pada hari rabu tanggal 14 maret 2018 sebanyak 530 kendaraan pada pukul 07.15 WIB - 16.15 WIB. Dalam menyelesaikan masalah ini maka direncanakan kebutuhan parkir sebanyak 530 SRP di karenakan angka tertinggi volume kendaraan terjadi pada hari rabu tanggal 14 maret 2018 sebanyak 530 kendaraan, sedangkan angka pergantian parkir yaitu 1 kendaraan/SRP/waktu pengamatan. Indeks parkir terbesar yang terjadi adalah $100 \%$. Luas areal bebas yang tersedia $936 \mathrm{~m}^{2}$. Luas areal parkir yang dibutuhkan $795 \mathrm{~m}^{2}$. Hal ini menunjukan bahwa luas areal bebas yang tersedia sudah dapat memenuhi kebutuhan areal parkir kendaraan siswa.
\end{abstract}

Kata kunci : Karakteristik, Parkir.

\begin{abstract}
SMK Negeri 5 Pekanbaru is one of the centers of activities in the field of services to manage education in the sub-district of Rumbai city Pekanbaru Riau province. One of the problems of SMK Negeri 5 Pekanbaru is the need of vehicle parking space for students. Although the School has adequate free land, in reality there are still many student vehicles parked at places that result in piling up of vehicles. This study aims to determine whether the free land that exist in SMK Negeri 5 Pekanbaru able to accommodate all vehicles students. The method of this research is conducted by survey at the location in question and from the existing data on the manager. Then analyzed parking characteristics such as: Parking volume, parking accumulation, turn over parking and parking index. The calculation results obtained in the volume of parking for motor vehicles on Monday, March 12, 2018 as many as 523 vehicles, for Tuesday, March 13, 2018 as many as 527 vehicles, for wednesday on March 14, 2018 as many as 530 vehicles, for Thursday 15 March 2018 as many as 523 vehicles and on Friday 16 March 2018 as many as 526 vehicles. The largest motor accumulation occurred on Wednesday, March 14, 2018 as many as 530 vehicles at 07:15 pm - 16:15 pm. In solving this problem, the planned parking requirement of $530 \mathrm{SRP}$ in because the highest number of vehicle volumes occurred on Wednesday, March 14, 2018 as many as 530 vehicles, while the number of parking turnover is 1 vehicle / SRP / time observation. The largest parking index is 100\%. Available free area of $936 \mathrm{~m}^{2}$. Parking space required $795 \mathrm{~m}^{2}$. This indicates that the area of available free area has been able to meet the needs of student parking lot.
\end{abstract}

Keywords: Characteristic, Parking.

Mukhardi, Analisis Areal Parkir pada SMK Negeri 5 Kota Pekanbaru 


\section{PENDAHULUAN}

SMK Negeri 5 Pekanbaru adalah sekolah menengah kejuruan negeri bidang industri teknologi dan rekayasa yang berlokasi di Jalan Yos Sudarso Rumbai, Pekanbaru, Riau. Sekolah ini telah berdiri sejak 1995 yang semula merupakan bagian dari STM Pekanbaru (SMK N 2 Pekanbaru). SMK Negeri 5 Pekanbaru merupakan salah satu sekolah menengah kejuruan yang banyak diminati di Pekanbaru, khususnya oleh masyarakat di kecamatan rumbai dan rumbai pesisir. Sampai saat ini jumlah siswa SMK Negeri 5 Pekanbaru sebanyak 1573 siswa yang terdiri dari 1194 siswa laki-laki dan 379 siswa perempuan yang terbagi dalam 11 jurusan yaitu Teknik Gambar Bangunan, Teknik Konstruksi Batu Beton, Teknik Pendinginan dan Tata Udara, Teknik Komputer dan Jaringan, Multimedia, Geologi Pertambangan, Teknik Audio Vidio, Teknik Pembangkit tenaga Listrik, Teknik Kendaraan Ringan, Teknik Sepeda Motor, dan Teknik Permesinan (Wakasarana, 2018).

Berdasarkan luas lahan SMK Negeri 5 Pekanbaru yaitu $36.000 \mathrm{~m}^{2}$, dengan lebar $170 \mathrm{~m}$ dan panjang $212 \mathrm{~m}$, sekolah ini memiliki beberapa infrastruktur pendukung diantaranya ruang kantor, ruang belajar, perpustakaan, laboratorium, ruang komputer, mushala, koperasi, lapangan sepakbola, lapangan volly, lapangan basket serta lainnya (Wakasarana, 2018), namun ada suatu hal yang kurang diperhatikan pihak sekolah yaitu masalah perparkiran. Melihat dari denah bangunan sekolah, SMK Negeri 5 Pekanbaru masih memiliki areal bebas seluas $936 \mathrm{~m}^{2}$.

Parkir adalah salah satu pendukung perkembangan sebuah institusi dimana parkir ini mempunyai peranan penting dalam menunjang kemajuan. Parkir yang tertata dengan baik dengan mengedepankan keamanan dan kenyamanan akan membuat para pengguna parkir tidak merasa khawatir terhadap kendaraan yang di parkirkannya. Mereka akan dapat melakukan aktifitas dengan maksimal tanpa terganggu dengan perasaan akan kehilangan kendaraannya.

Seiring dengan peningkatan jumlah penduduk dan lajunya peningkatan perekonomian di Pekanbaru mendorong masyarakat untuk memiliki kendaraan pribadi. Rata-rata di era modern ini khususnya siswa di SMK Negeri 5 Pekanbaru telah banyak menggunakan kendaraan sepeda motor ke sekolah. Semuanya itu tergantung dari faktor ekonomi masing-masing siswa dan jarak dari rumah ke sekolah para siswa. Dengan meningkatnya jumlah siswa dengan moda kendaraan roda dua menyebabkan peningkatan kebutuhan lahan parkir di tempat-tempat tertentu yang salah satunya adalah kawasan SMK Negeri 5 Pekanbaru. Terhitung hingga tahun ajaran 2017/2018 berdasarkan pengamatan langsung di lokasi SMK Negeri 5 Pekanbaru, bahwa sekolah ini sudah memiliki areal parkir, akan tetapi areal parkir yang tersedia hanya untuk guru, karyawan dan tamu saja, dan untuk parker kendaraan siswa sekolah ini tidak ada. Akibatnya setiap hari terjadi penumpukan kendaraanyang tidak tertata dengan rapi dihalaman sekolah. Hal ini dapat mengganggu atau menghambat kendaraan yang akan keluar saat pulang sekolah di sebabkan menumpuknya kendaraan berparkir, dan sebagian siswa untuk mengatasi ini lebih memilih untuk parkir kendaraan motornya diluar lingkungan sekolah, akan tetapi hal ini dapat mengakibatkan kerawanan kehilangan sepeda motor siswa. Hal ini membuktikan bahwa SMK Negeri 5 Pekanbaru belum memiliki areal parkir yang mampu menampung kendaraan siswa. 


\section{METODE PENELITIAN}

Dalam suatu analisa maupun perencanaan transportasi, pengumpulan data merupakan salah satu tahapan yang sangat penting, tujuan dari tahap pengumpulan data dalam penelitian ini adalah untuk mendapatkan seluruh data mentah yang akan digunakan dalam analisis, data yang dikumpul kan dalam penelitian ini adalah data primer dan data sekunder. Berdasarkan hasil survei pendahuluan yang dilakukan, maka pengambilan data survei lapangan dilakukan selama 6 (Enam) hari Senin tanggal 12 Maret 2018 sampai jum'at tanggal 16 April 2018.

1. Data Primer

Data primer adalah data yang diperoleh dari survei dilokasi penelitian. Survei yang dilakukan tersebut akan memperoleh data-data yang nyata sesuai kondisi dilapangan .

2. Data Skunder

Pengumpulan data sekunder diperoleh dari instansi terkait, dalam penelitian ini data sekunder berasal dari SMK Negeri 5 Pekanbaru. Adapun data sekunder yang dibutuhkan untuk penelitian ini meliputi:
a. Denah bangunan sekolah
b. Luas lahan sekolah
c. Satuan ruang parkir
d. Standar- standard dan asumsi perparkiran

\section{Alat Yang Digunakan}

1. Alat-alat tulis untuk pencatatan data

2. Formulir-formulir pencatatan dan pengolah data

3. Tenaga surveyor

4. Jam yang digunakan untuk penunjuk waktu siklus yang ada
5. Kamera untuk pengambilan gambar pada kondisi-kondisi tertentu

6. Laptop atau komputer sebagai penunjang proses pengolahan data.

\section{Bagan Alir Penelitian}

Bagan alir penelitian ini dapat dilihat pada gambar 1.

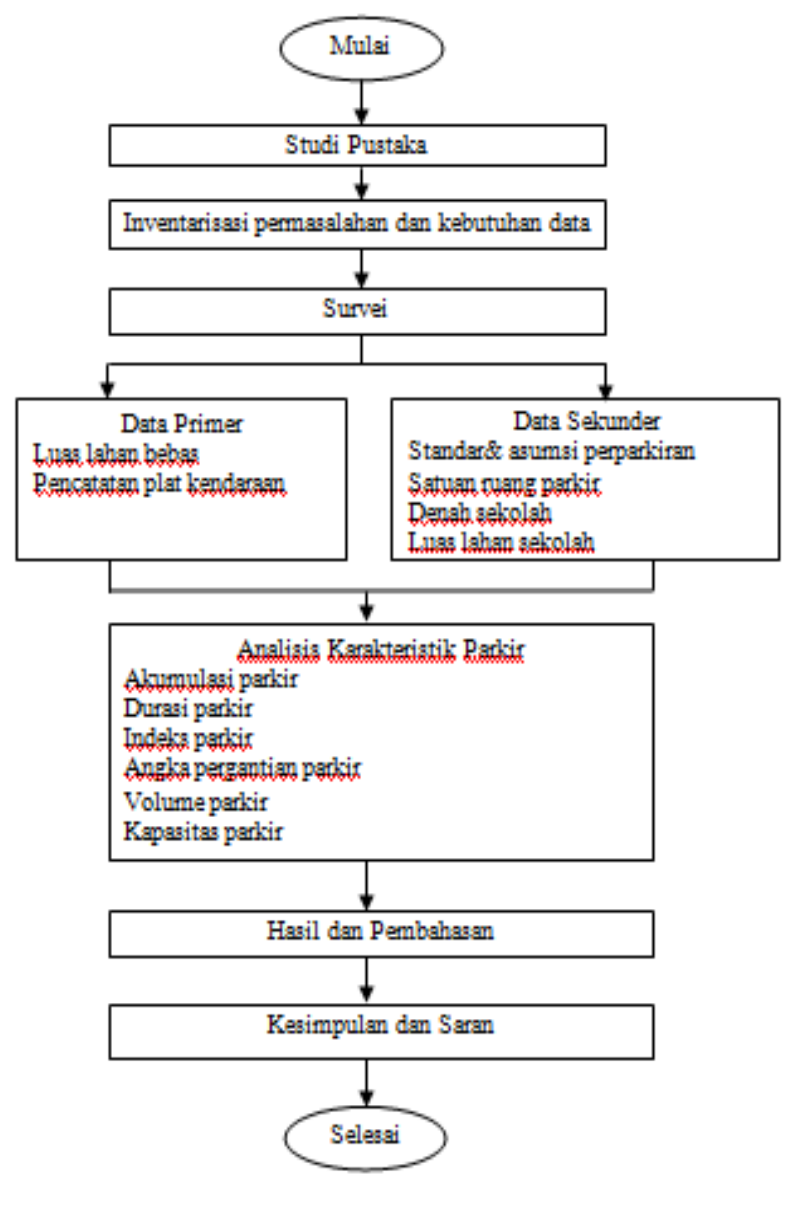

Gambar 1. Bagan Alir Penelitian

\section{HASIL DAN PEMBAHASAN}

\subsection{Volume Parkir}

Data hasil survei jumlah kendaraan siswa yang dilakukan selama enam hari yakni dimulai pada hari senin tanggal 12 maret 2018 sampai hari jum'at tanggal 16 april 2018. 
Table 1. Jumlah kendaraan roda dua yang parkir di Negeri 5 Pekanbaru

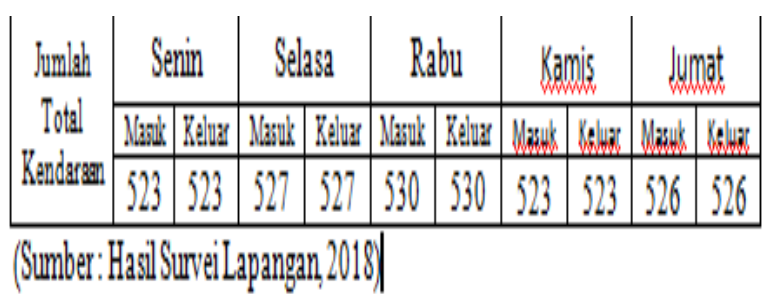

\subsection{Akumulasi Parkir}

Akumulasi parkir dihitung untuk mengetahui jumlah kendaraan yang parkir dengan sela waktu tertentu. Akumulasi dihitung dengan menjumlahkan kendaraan yang sedang parkir dengan kendaraan yang masuk kemudian dikurangkan dengan kendaraan yang keluar.

Akumulasi tertinggi kendaraan roda dua terdapat pada hari Rabu 14 Maret 2018 dan dapat dilihat pada tabel 2 .

Table 2. Perhitungan akumulasi parkir di SMK Negeri 5 Pekanbaru hari Rabu tanggal 14 Maret 2018

\begin{tabular}{|c|c|c|c|c|}
\hline \multirow{2}{*}{ No } & \multirow{2}{*}{ Waktu } & \multicolumn{3}{|c|}{ Sepeda motor penguniung } \\
\hline & & Masuk & Keluar & Akumulasi \\
\hline 1 & $06.30-06.45$ & 62 & 0 & 61 \\
\hline 2 & $06.45-07.00$ & 173 & 0 & 245 \\
\hline 3 & $07.00-07.15$ & 261 & 0 & 518 \\
\hline 4 & $07.15-07.30$ & 31 & 0 & 530 \\
\hline 5 & $07.30-16.15$ & 0 & 0 & 530 \\
\hline 6 & $16.15-16.30$ & 0 & 4 & 527 \\
\hline 7 & $16.30-16.45$ & 0 & 351 & 172 \\
\hline 8 & $16.45-17.00$ & 0 & 168 & 5 \\
\hline 9 & $17.00-17.15$ & 0 & 4 & 1 \\
\hline 10 & $17.15-17.30$ & 0 & 0 & 0 \\
\hline \multicolumn{2}{|c|}{ Jumlah Total } & 527 & 527 & 2589 \\
\hline
\end{tabular}

(Sumber: Hasil SurveiLapangan, 2018)

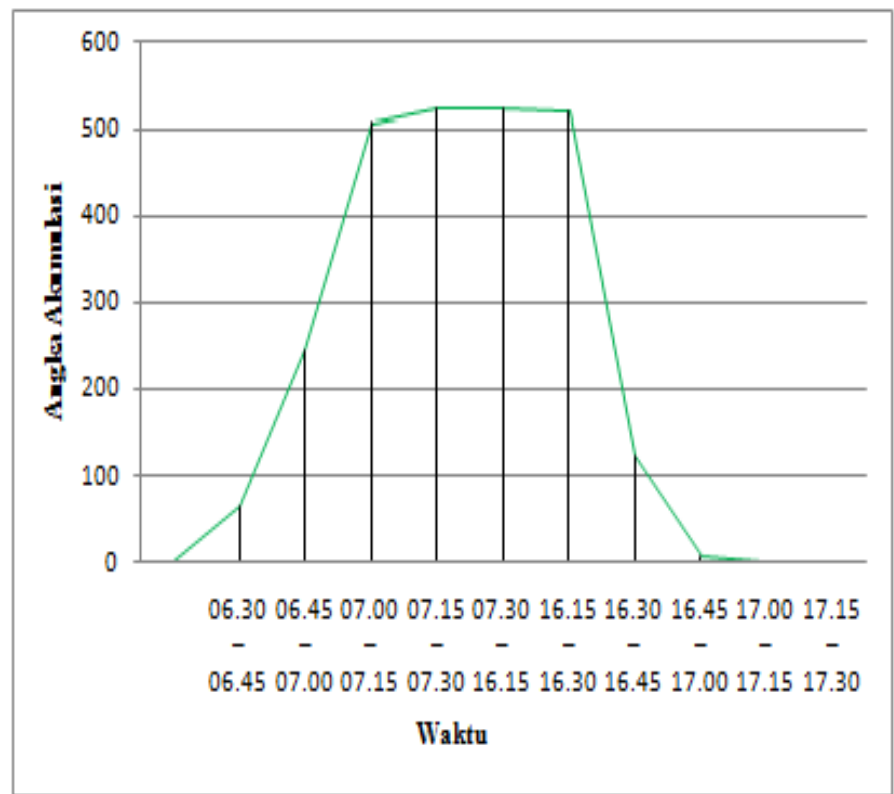

Gambar 2. Grafik Akumulasi Parkir Kendaraan di SMK Negeri 5 Pekanbaru Rabu 14 Maret 2018.

\subsection{Index Parkir}

Indeks parkir yaitu besarnya penggunaan ruang parkir yang dihitung dari jumlah kendaraan yang diparkir dibagi dengan jumlah total ruang parkir. Tujuan perhitungan indeks parkir ini adalah untuk mengetahui presentase penggunaan ruang parkir pada setiap periode waktu. Kapasitas ruang parkir yang terdapat di SMK Negeri 5 Pekanbaru dengan jenis kendaraan sepeda motor adalah 530 petak parkir. Diambil dari volume maksimum kendaraan yang parkir di SMK Negeri 5 Pekanbaru pada hari rabu 14 maret 2018

Misal, pada hari rabu 14 Maret 2018 jumlah kendaraan yang masuk pada pukul 06.30 WIB pukul 06.45 WIB sebesar 61 sepeda motor, dengan ruang parkir sebanyak 530 kendaraan. Maka:

$$
\text { Indeks parkir } \quad=\frac{61 \times 100 \%}{530}=11,5 \%
$$


Tabel 3. Perhitungan Indeks parkir di SMK Negeri 5 Pekanbaru hari Rabu tanggal 14 Maret 2018

\begin{tabular}{|c|c|c|c|}
\hline No & Waktu & Akumulasi & IP $(\%)$ \\
\hline 1 & $06.30-06.45$ & 61 & 11.50 \\
\hline 2 & $06.45-07.00$ & 245 & 46.22 \\
\hline 3 & $07.00-07.15$ & 518 & 97.73 \\
\hline 4 & $07.15-07.30$ & 530 & 100 \\
\hline 5 & $07.30-16.15$ & 530 & 100 \\
\hline 6 & $16.15-16.30$ & 527 & 99.43 \\
\hline 7 & $16.30-16.45$ & 172 & 32.45 \\
\hline 8 & $16.45-17.00$ & 5 & 0.94 \\
\hline 9 & $17.00-17.15$ & 1 & 0.18 \\
\hline 10 & $17.15-17.30$ & 0 & 0 \\
\hline
\end{tabular}

(Sumber: Hasil SurveiLapangan, 2018)

\subsection{Angka Pergantian Parkir}

Angka pergantian parkir adalah nilai perbandingan antara volume maksimum kendaraan dengan jumlah petak parkir. Di kerenakan volume maksimum kendaraan terjadi pada hari rabu tanggal 14 maret 2018 sebanyak 530 kendaraan maka ruang parkir yang di rencanakan sebanyak 530 petak parkir.

Perhitungan angka pergantian parkir dapat dilihat pada tabel 4 .

\begin{tabular}{|c|c|c|c|}
\hline $\begin{array}{c}\text { Hari } \\
\text { (a) }\end{array}$ & $\begin{array}{c}\text { Akumulasi } \\
(\text { b })\end{array}$ & $\begin{array}{c}\text { Ruang Paxkir Rencana } \\
\text { (c) }\end{array}$ & $\begin{array}{c}\text { Parkir Tum over } \\
(\mathrm{d}=6 \mathrm{c})\end{array}$ \\
\hline Rabu & 530 & 530 & 1 \\
\hline
\end{tabular}

(Sumber: Hasil Survei Lapangan, 2018)

Dari tabel di atas di dapat angka pergantian parkir yaitu 1 kendaraan untuk satu petak parkir, di karenakan tidak ada kendaraan yang keluar masuk areal parkir. Pada umumnya ,kendaran siswa parkir dalam jangka panjang. Kendaraan yang sudah masuk di pagi hari, keluarnya pada sore hari atau pada jam pulang sekolah.

Secara teori menurut Direktorat Jendral Perhubungan Darat 1998, kebutuhan SRP di sekolah dengan rincian jumlah siswa 3000 mempunyai SRP minimum sebesar 60 SRP, dan jumlah siswa 4000 mempunyai SRP minimum 80 SRP. Berdasarkan data tersebut maka teori ini tidak dapat digunakan dikarenakan jumlah volume maksimum yang parkir pada SMK Negeri 5 Pekanbaru adalah sebanyak 530 kendaraan dengan jumlah 1573 siswa. Jadi kebutuhan ruang parkir yang digunakan berdasarkan rumusan masalah adalah 530 SRP sesuai dengan data saat ini, maka dapat diperoleh luasan ruang parkir yang harus disediakan dengan perhitungan sebagai berikut.

Jumlah kendaraan maksimum : 530 (pada hari $\mathrm{rabu})$

SRP sepeda motor (Tabel 2.2) : 0,75 $\mathrm{m} \times 2 \mathrm{~m}$

Luasan ruang parkir rencana : $530 \times 0,75 \times 2=$ $795 \mathrm{~m}^{2}$

Berdasarkan perhitungan diatas maka luasan ruang parkir yang dibutuhkan dapat terpenuhi, dikarenakan total lahan bebas yang dimiliki SMK Negeri 5 Pekanbaru adalah sebesar $936 \mathrm{~m}^{2}$

\section{Pembahasan}

Penelitian ini dilakukan pada SMK Negeri 5 Pekanbaru, berdasarkan lahan bebas yang tersedia untuk parkir sepeda motor mencukupi untuk menampung seluruh kendaraan siswa.

Untuk volume kendaraan siswa pada hari senin 12 Maret 2018 dari pukul 06.30 WIB pukul 17.30 WIB mengalami peningkatan pada pukul 07.00 WIB - pukul 07.15 WIB sebanyak 262, hal ini terjadi karena sekolah ini memulai aktivitas belajar mengajar pada pukul 07.15 WIB. sehingga para siswa diwajibkan hadir sebelum pukul 07.15 WIB. Untuk kendaraan yang keluar area parkir dari pukul 06.30 WIB - pukul 17.30 WIB mengalami puncaknya pada pukul 16.30 
WIB - pukul 16.45 WIB sebanyak 398 kendaraan, ini dikarenakan aktivitas belajar mengajar pada sekolah ini berakhir pada puku 16.30 WIB, sedangkan untuk hari Selasa jumlah volume parkir dengan jenis kendaraan motor mengalami peningkatan pada pukul 07.00 WIB - pukul 07.15 WIB sebanyak 261. Untuk kendaraan yang keluar area parkir mengalami puncaknya pada pukul 16.30 WIB - pukul 16.45 WIB sebanyak 351 kendaraan, untuk hari Rabu jumlah volume parkir dengan jenis kendaraan motor mengalami peningkatan pada pukul 07.00 WIB - sampai 07.15 WIB sebanyak 273. Untuk kendaraan yang keluar area parkir mengalami puncaknya pada pukul 16.30 WIB - pukul 16.45 WIB sebanyak 355 kendaraan. Untuk hari Kamis jumlah volume parkir dengan jenis kendaraan motor mengalami peningkatan pada pukul 07.00 WIB - sampai 07.15 WIB sebanyak 277. Untuk kendaraan yang keluar area parkir mengalami puncaknya pada pukul 16.30 WIB - pukul 16.45 WIB sebanyak 304 kendaraan dan pada hari Jumat jumlah volume parkir dengan jenis kendaraan motor mengalami peningkatan pada pukul 07.00 WIB - sampai 07.15 WIB sebanyak 232. Untuk kendaraan yang keluar area parkir mengalami puncaknya pada pukul 11.15 WIB - pukul 11.30 WIB sebanyak 246 kendaraan, dibandingkan dengan penelitian terdahulu yang dilakukan oleh Rayhan M (2017) yaitu Volume parkir, dari hasil perhitungan survei lapangan bahwa volume parkir sepeda motor maksimum terjadi pada hari senin dengan jumlah kendaraan 223 kendaraan. Akumulasi parkir, dari data hasil survei pada hari selasa 18 April 2017, Rabu 19 April 2017 dan Kamis 20 April 2017 di dapat akumulasi parkir motor dengan maksimal terjadi pada hari selasa yaitu sebesar 221 kendaraan. Tingkat pergantian parkir yang diperoleh adalah 1 kendaraan untuk setiap satu petak SRP. Parkir ini direncanakan disebelah timur sekolah dengan volume kendaraan rencana 223 kendaraan dengan luas tiap satuan ruang parkirnya $0,75 \mathrm{~m}$ x 2,00 $\mathrm{m}$ dengan menggunakan pola parkir pulau tulangan tipe B dengan sudut $45^{\circ}$, perbedaannya pada penelitian yang dilakukan oleh Muhammad Rayhan yaitu merencanakan areal parkir pada MTs Negeri 5 Tambusai Utara, sedangkan penelitian yang saya lakukan hanya menganalisis kebutuhan ruang parkir kendaraan siswa di SMK Negeri 5 pekanbaru berdasarkan luas areal bebas yang tersedia.

Pada penelitian Tukiman (2015) yaitu pada luasan parkir di sekolah umumnya masih ada kemungkinan bisa di kembangkan asal dalam mengembangkanya memperhatikan efektifitas lahan, misalnya bisa dilakukan bertingkat, pengelolaan parkir masih sederhana, apabila dengan manajemen yang baik dapat lebih efektif, sedang keamanan parkir meskipun manajemen yang sederhana rata- rata sekolah yang dipakai penelitian ini masih relatif aman. Perbedaan penelitian Tukiman yaitu untuk mendapatkan alternatif solusi bagi para pengelola sekolah agar fasilitas parkir di sekolah agar dapat meningkatkan pelayanan dan peningkatan mutu sekolah, dan meningkatkan rasa aman para siswa untuk memarkirkan kendaraannya tanpa ada rasa takut kehilangan kendaraan para siswa. Sedangkan pada penelitian yang saya lakukan yaitu untuk mengetahui kebutuhan areal parkir kendaraan siswa di SMK Negeri 5 Pekanbaru.

\section{KESIMPULAN DAN SARAN}

\section{Kesimpulan}

Berdasarkan hasil pembahasan dan analisis data yang telah dilakukan terhadap areal parkir kendaraan sepeda motor siswa di SMK Negeri Pekanbaru, dapat disimpulkan bahwa luasan ruang parkir yang di butuhkan dapat terpenuhi dengan 
luas areal parkir sebesar $795 \mathrm{~m}^{2}$, dan luas areal bebas yang dimiliki SMK Negeri 5 Pekanbaru sebesar $936 \mathrm{~m}^{2}$.

\section{Saran}

Adapun saran yang dapat saya sampaikan pada penelitian yang saya lakukan di SMK Negeri 5 Pekanbaru yaitu:

1. Agar pihak sekolah segera membangun areal parkir untuk kendaraan siswa, sehingga tidak terjadi penumpukan kendaraan di halaman sekolah.

2. Setelah areal parkir dibangun, garis petak parkir harus dibuat sehingga memudahkan pengendara atau pengguna parkir untuk memarkirkan kendaraan dengan baik dan juga menghindari pemborosan tempat parkir.

3. Diperlukan rambu-rambu agar perparkiran lebih teratur.

\section{UCAPAN TERIMAKASIH}

Penulis mengucapkan terimakasih kepada :

1. Kedua orang tua tercinta, dan seluruh keluarga besar yang selalu memberikan dukungan, semangat dan doa.

2. Bapak Hamzah, S.T., M.T., Ph.D. selaku Dekan Fakultas Teknik Universitas Lancang Kuning.

3. Bapak Fadrizal Lubis, S.T., M.T. selaku Ketua Program Studi Teknik Sipil Universitas Lancang Kuning Pekanbaru dan selaku dosen pembimbing II yang telah memberikan bimbingan serta arahan selama penulisan tugas akhir ini hingga selesai.

4. Bapak Ir. Virgo Trisep Haris,M.T. selaku dosen pembimbing I yang telah menyediakan waktu, tenaga, dan pikiran untuk membimbing penulis dalam penyusunan tugas akhir ini.

5. Bapak Zainuri, S.T.,M.T., Ibu Shanti Wahyuni Megasari, S.T., M.Eng, dan ibu Winayati, S.T, M.T. selaku Dosen Penguji yang memberikan kritik dan masukan untuk menyempurnakan tugas akhir ini.

Akhir kata, penulis berharap Allah SWT membalas segala kebaikan kepada semua pihak yang telah membantu. Semoga tugas akhir ini membawa manfaat bagi penulis, dan pembaca untuk pembangunan ilmu pengetahuan.

\section{DAFTAR PUSTAKA}

Annam CK. 2011. Analisis Kapasitas Ruang Parkir Sepeda Motor Off Street Rumah Sakit Telogorejo Semarang (Tugas Akhir). Semarang: Program Sarjana S1, Universitas Negeri Semarang.

Budiarto. 2007. Analisis Model Kebutuhan Parkir Sepeda motor. (Tugas Akhir). Malang: Program Sarjana S1, Universitas Negeri Malang.

Direktorat Jenderal Perhubungan Darat. 1998. Pedoman Perencanaan dan Pengoperasian Fasilitas Parkir. Jakarta: Direktorat Jenderal Perhubungan Darat.

Rayhan M. 2017. Perencanaan Areal Parkir Sepeda Motor Pada Sekolah MTs Negeri 5 Tambusai Utara Kabupaten Rokan Hulu (Tugas Akhir). Pekanbaru: Program Sarjana S1, Universitas Lancang Kuning.

Tukiman. 2015. Fasilitas Parkir Sepeda Motor di Sekolah. Malang: Pusat Pengembangan dan Pemberdaya Pendidikan. 
Undang - Undang Republik Indonesia Nomor 22 tahun 2009. tentang Lalu Lintas dan Angkutan Jalan. Jakarta: Keptusan Presiden. 